\title{
B-Arrestin 2-Mediated Immune Suppression Induced by Chronic Stress
}

\author{
Hui Li ${ }^{\mathrm{a}}$ Dean Andrew Smalligan ${ }^{\mathrm{a}}$ Nanchang Xie $^{\mathrm{a}}$ Avani Javer $^{\mathrm{a}} \quad$ Yi Zhang $^{\mathrm{a}}$ \\ Gregory Hanley ${ }^{b}$ Deling Yin ${ }^{a}$ \\ ${ }^{a}$ Department of Internal Medicine and ${ }^{b}$ Division of Laboratory Animal Resources, James Quillen College of \\ Medicine, East Tennessee State University, Johnson City, Tenn., USA
}

\section{Key Words}

Immunosuppression · PI3K · Restraint stress · Splenocyte

reduction $\cdot \beta$-Arrestin 2

\begin{abstract}
Objective: Stress, either physical or psychological, can modulate immune function. However, the mechanisms associated with stress-induced immune suppression remain to be elucidated. $\beta$-Arrestin 2 serves as adaptor, scaffold, and/or signal transducer. The role of $\beta$-arrestin 2 in stress-induced immune suppression is not known yet. Methods/Results: Here, we demonstrate that $\beta$-arrestin 2 deficiency in mice increases the sensitivity to the chronic stress-induced reduction in the number of splenocytes. Interestingly, the stressinduced suppression of T helper-type (Th) 1 cytokines and the increased production of Th2 cytokines were greatly enhanced in $\beta$-arrestin 2-deficient mice compared with wildtype mice. Moreover, inhibition of PI3K in $\beta$-arrestin 2-deficient mice exerts an additive effect on the stress-induced reduction in the number of splenocytes. Conclusion: Our study demonstrates that a deficiency in $\beta$-arrestin 2 augments stress-induced immune suppression.
\end{abstract}

Copyright $\odot 2011$ S. Karger AG, Basel

\section{KARGER}

Fax +41613061234

E-Mail karger@karger.ch

www.karger.com
(C) 2011 S. Karger AG, Basel

Accessible online at:

www.karger.com/nim

\section{Introduction}

Many studies have shown that stress has profound effects on immunological parameters in humans and animals $[1,2]$. These effects include lymphocytopenia, leukocyte subset distribution, cytokine production, natural killer cell activity, and macrophage maturation and activity. These changes may result from physiological alterations or from psychological stress $[2,3]$. However, the effects of stress, which may occur on a daily basis, varies with the severity of the stress. It is generally believed that chronic stress inhibits immune function and increases susceptibility to diseases [4-8]. This effect is at least in part due to the reduction in splenocytes numbers [9-12]. Stress is a known risk factor for numerous human diseases, such as infectious diseases, autoimmune diseases and cancer $[4-6,13]$. The understanding of the cellular mechanisms underlying the suppressive effects of stress on the immune system has increased as we have reported that physical stress modulates the immune system through Toll-like receptors (TLRs) and the cell death receptor Fas-mediated apoptotic mechanism [5, 10, 11, 14]. Moreover, we have shown that phosphoinositide 3-kinases (PI3Ks) participate in chronic stress-induced immune suppression $[8,12]$. However, the precise mechanisms associated with stress-induced immune suppression remain to be elucidated. 
Arrestins, which consist of four classes, visual arrestin, cone arrestin, $\beta$-arrestin 1 and $\beta$-arrestin 2 , play a fundamental role in G-protein-coupled receptor regulation [15-17]. Both $\beta$-arrestin 1 and 2, two universally expressed members of the arrestin family in many tissues $[15,17]$ with especially high expression in lymphatic and nervous tissues, are key negative regulators and scaffolds of G-protein-coupled receptor signaling $[15,18,19]$. Recent reports reveal that $\beta$-arrestins function as adapters to connect the receptors to the cellular trafficking machinery [15, 17-19]. However, relatively little is known about the importance of $\beta$-arrestin 2 in vivo in the immune system, where it is abundantly expressed.

$\beta$-Arrestin 2 plays an important role in the regulation of T lymphocytes [19]. Increasing evidence demonstrated that $\beta$-arrestin 2 mediates some important immune responses, such as the regulation of chemotactic responses and granule release due to its scaffold and adaptor functions [17-19]. Accumulating evidence reveals that $\beta$-arrestin plays a critical role in preventing apoptosis $[15,20]$. For example, stimulation of various G-protein-coupled receptors causes apoptosis in the absence of, but not in the presence of, $\beta$-arrestins, indicating an important role for $\beta$-arrestins in anti-apoptotic signaling. Recent studies have disclosed that $\beta$-arrestins are fundamental negative regulators of innate immune activation [21]. Remarkably, $\beta$-arrestin 2-deficient mice are more susceptible to endotoxic shock, suggesting $\beta$-arrestin 2 functions in vivo [21]. However, the role of $\beta$-arrestin 2 in stress-induced immune responses is not known yet. Our previous studies have shown that PI3K signaling participates in the stress-induced reduction in the number of splenocytes $[8,12]$.

PI3Ks are a conserved family of signal transduction enzymes which are involved in the regulation of cell proliferation and inhibition of cell apoptosis [22]. PI3K is an enzyme complex composed of a regulatory subunit (p85) and a catalytic subunit (p110) [23]. In the immune system, impaired PI3K signaling leads to immunodeficiency, whereas unrestrained PI3K signaling contributes to autoimmunity and leukemia [24]. The PI3K inhibitors LY294002 and wortmannin have been used extensively as research tools. Intriguingly, recent studies reported that inhibition of PI3K with LY294002 or wortmannin completely eliminated the protection against septic mortality, which resulted in increased serum levels of TNF- $\alpha$, IL-2, and IL- 6 in septic mice. They also reported that inhibition of PI3K in septic mice resulted in increased splenocyte apoptosis [25]. Recent evidence has shown that pretreatment of neutrophils with the PI3K inhibitor
LY294002 totally reversed the delay in apoptosis induced by heme [26-28], and recent studies revealed that $\beta$-arrestin 2 regulates the PI3K/Akt signaling pathway [29]. In this study, we investigated the role of $\beta$-arrestin 2 and the involvement of PI3K signaling in the immune response following stress. Our results showed that $\beta$-arrestin 2 plays a critical role in stress-induced immune suppression.

\section{Materials and Methods}

\section{Mice}

Wild-type C57BL/6 mice were obtained from the Jackson Laboratory (Bar Harbor, Me., USA). The $\beta$-arrestin 2 knockout mouse line was a generous gift from Dr. Robert Lefkowitz (Duke University Medical Center, Durham, N.C., USA) and maintained in the Division of Laboratory Animal Resources at the East Tennessee State University (ETSU), a facility accredited by the Association for the Assessment and Accreditation of Laboratory Animal Care International. All aspects of the animal care and experimental protocols were approved by the ETSU Committee on Animal Care.

\section{Physical Restraint Stress and Administration of Reagents}

Six- to 7-week-old male mice were subjected to an established chronic physical restraint protocol used in our laboratory as well as others $[8,10-14,30]$. Briefly, mice were placed in a $50-\mathrm{ml}$ conical centrifuge tube with multiple punctures to allow ventilation. Mice were held horizontally in the tubes from 9:00 p.m. to 9:00 a.m. for $12 \mathrm{~h}$ followed by a 12 -hour rest. The light cycle for the mice was from 7 a.m. (on) to 7 p.m. (off). During the rest period, food and water were provided ad libitum. Control littermates were kept in their original cage, and food and water were provided only during the 12-hour rest. Animals received a single intraperitoneal injection of LY294002, a PI3K inhibitor [8, 12] (1 mg/ 25 g body weight; Sigma, St. Louis, Mo., USA). Two days after physical stress, mice were sacrificed by $\mathrm{CO}_{2}$ asphyxiation, and the spleens and splenocytes were collected immediately after stress exposure. Mice were subjected to a 12-hour physical restraint daily for 2 or 3 days, and delayed-type hypersensitivity (DTH; hind footpad) of all groups was measured as described below.

\section{Isolation of RNA and RT-PCR}

Total RNA was isolated from spleens by the Versagene ${ }^{\text {TM }}$ RNA tissue kit (Gentra Systems, Minneapolis, Minn., USA), as described in our previous studies [11]. The real-time RT-PCR detection technique was performed as described previously [11]. Briefly, first-strand cDNA was synthesized from $1 \mu \mathrm{g}$ of total RNA in a final volume of $50 \mu \mathrm{l}$ using a Reaction Ready ${ }^{\mathrm{TM}}$ first-strand cDNA synthesis kit (SABioscience Corporation, Frederick, Md., USA). PCR was performed in a $50-\mu$ l volume using $\mathrm{RT}^{2}$ realtime ${ }^{\mathrm{TM}}$ SYBR Green Fluorescein PCR Master Mix (SABioscience). All primers were purchased from SABioscience. All PCR assays were performed in triplicate. The reaction conditions were: $95^{\circ} \mathrm{C}$ for $12 \mathrm{~min}$, followed by 40 cycles at $95^{\circ} \mathrm{C}$ for $15 \mathrm{~s}, 55^{\circ} \mathrm{C}$ for $30 \mathrm{~s}$, and $72^{\circ} \mathrm{C}$ for $30 \mathrm{~s}$. Threshold cycle numbers $\left(C_{\mathrm{T}}\right)$ were determined using the Bio-Rad iCycler iQ multicolor real-time PCR detection 


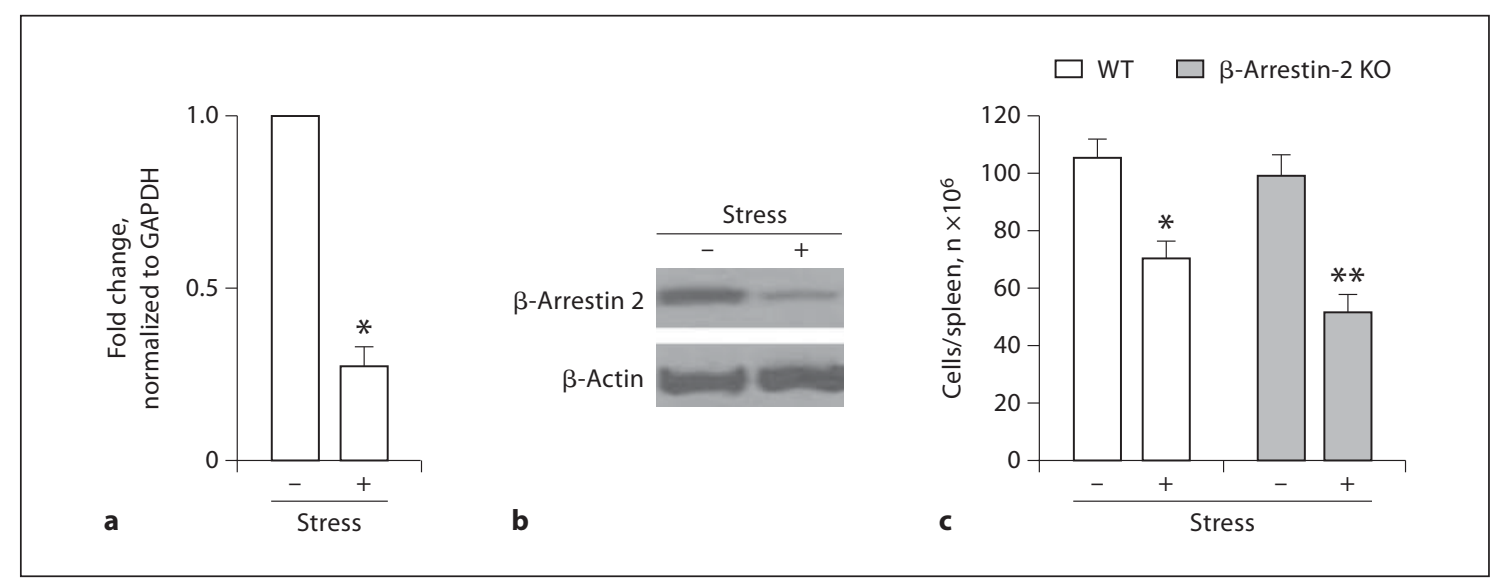

Fig. 1. Effect of $\beta$-arrestin 2 in physical stress-induced splenocyte reduction. a Physical restraint decreased the expression of $\beta$-arrestin 2. Wild-type C57BL/6J (WT) mice at 7 weeks of age were stressed for $12 \mathrm{~h}$. Total RNA was isolated from the spleen and analyzed for $\beta$-arrestin 2 expression by real-time quantitative RTPCR. b WT mice were subjected to a 12-hour physical restraint daily for 2 days. The expression of $\beta$-arrestin 2 was determined by Western blot analysis. c $\beta$-Arrestin 2 knockout mice ( $\beta$-arrestin $2 \mathrm{KO}$ ) and WT mice aged 6-7 weeks were subjected to a 12-hour physical restraint daily for 2 days. Total splenocytes were counted. ${ }^{*} \mathrm{p}<0.01$ vs. unstressed control, ${ }^{* *} \mathrm{p}<0.01$ vs. stressed WT. Means and SE were calculated from 7 mice/group. system (version 1.1) and transformed using the $\Delta C_{\mathrm{T}}$ comparative method. Gene-specific expression values were normalized to expression values of GAPDH and/or $\beta$-actin (endogenous control) within each sample. The amount of target, normalized to an endogenous reference and relative to a calibrator, was determined by the comparative $C_{\mathrm{T}}$ method $\left(\Delta \Delta C_{\mathrm{T}}\right)$.

\section{Western Blot Analysis}

Cytoplasmic proteins were prepared from splenic tissue and immunoblots were performed as described in our previous studies $[8,31,32]$. Briefly, the cellular proteins were separated by SDSPAGE and transferred onto Hybond ECL membranes (Amersham Pharmacia, Piscataway, N.J., USA). The membrane was then incubated at room temperature in a blocking solution composed of $5 \%$ skim milk powder dissolved in $1 \times$ TBS (10 mM Tris, $\mathrm{pH} 8.0$ and $140 \mathrm{mM} \mathrm{NaCl}$ ) for $1 \mathrm{~h}$. The membrane was then incubated with the blocking solution containing anti- $\beta$-arrestin 2 antibody overnight at $4^{\circ} \mathrm{C}(\beta$-arrestin 2 antibody was obtained from Santa Cruz Biotechnology, Santa Cruz, Calif., USA). After washing three times with TBS for $5 \mathrm{~min}$, the blot was then incubated with a second antibody. The blot was again washed three times with TBS before being exposed to the SuperSignal West Dura Extented Duration substrate (Pierce Biotechnology, Rockford, Ill., USA).

\section{ELISA for Cytokines}

Splenic lymphocytes from $\beta$-arrestin 2 knockout and wildtype mice were adjusted to a final concentration of $5 \times 10^{5}$ cells/ $\mathrm{ml}$ in 96-well plates. Splenocytes were treated with concanavalin A $(5 \mu \mathrm{g} / \mathrm{ml})$. The supernatants were harvested after $24 \mathrm{~h}$ (IL-2 and IFN- $\gamma$ detection) or $48 \mathrm{~h}$ (IL-4) of cultivation. The presence of cytokines in the supernatants was determined using cytokinespecific sandwich ELISA kits (R\&D Systems, Minneapolis, Minn., USA), as described in our previous studies $[8,14]$.
Induction of DTH

DTH was induced as described previously $[4,33,34]$. Briefly, 7- to 8-week-old mice were immunized with ovalbumin (OVA, injection of $100 \mu \mathrm{g}$ s.c.) in complete Freund's adjuvant on the 1st day of stress which was followed by a boost with OVA (injection of $20 \mu \mathrm{g}$ s.c.) in incomplete Freund's adjuvant on the 7 th day. Mice were subjected to a 12-hour physical restraint daily for 2 or 3 days. DTHs (hind footpad) of all groups were measured on day 10 in a blinded fashion using a caliper meter.

Statistical Analysis

The results were presented as means $\pm \mathrm{SD}$. The data were analyzed using one-way analysis of variance followed by Bonferroni tests to determine where differences among groups existed. A value of $\mathrm{p}<0.05$ was considered statistically significant.

\section{Results}

\section{$\beta$-Arrestin 2 Deficiency in Mice Increases the Sensitivity to the Stress-Induced Reduction in Splenocyte Numbers}

Recently, our studies have revealed that $\beta$-arrestin 2 plays a role in apoptosis [35-37]. Our previous studies have shown that restraint stress induces a reduction in splenocyte numbers $[8,10,12,14]$. Our previous studies have demonstrated that restraint stress of mice induces a reduction in splenocyte numbers through a cell-apoptotic mechanism [10]. To determine the role of $\beta$-arrestin 2 in the restraint stress-induced reduction in splenocyte 


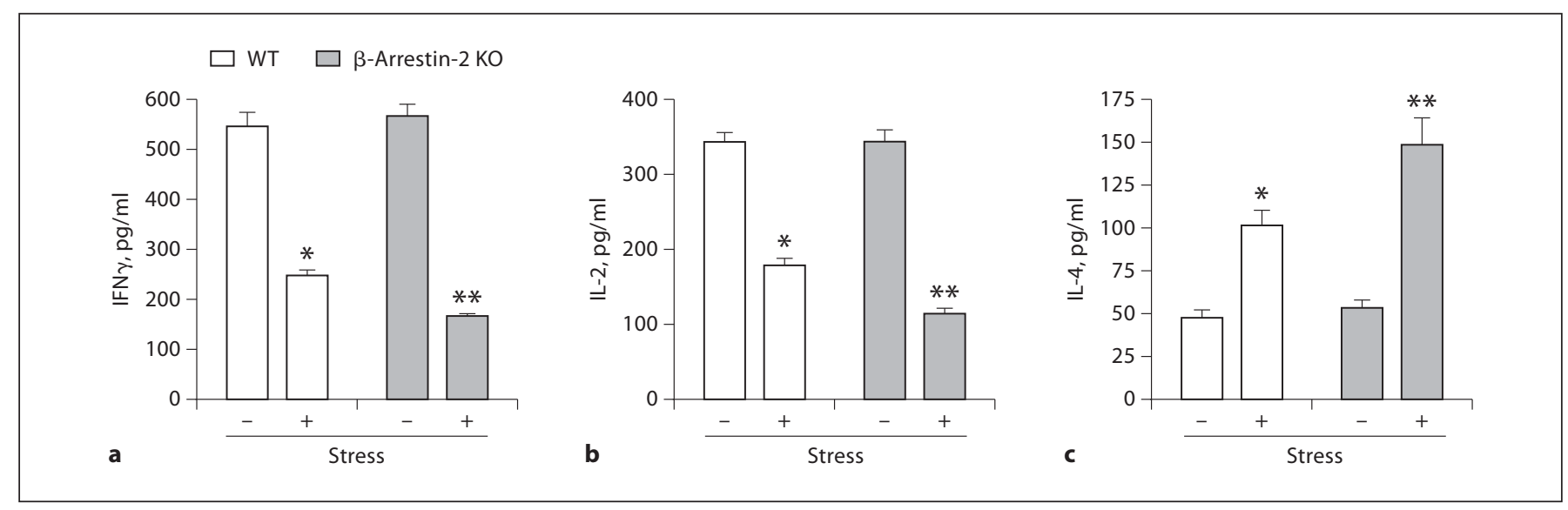

Fig. 2. Effect of $\beta$-arrestin 2 on Th1 and Th2 cytokine levels following restraint stress. Both wild-type (WT) and $\beta$-arrestin 2 -deficient ( $\beta$-arrestin $2 \mathrm{KO}$ ) mice aged $6-8$ weeks were subjected to a 12 -hour physical restraint stress for 2 days. Splenic lymphocytes were treated with concanavalin A $(5 \mu \mathrm{g} / \mathrm{ml})$ for $24 \mathrm{~h}$ (IFN- $\gamma$ and
IL-2 detection) or $48 \mathrm{~h}$ (IL-4). Production of the Th1 cytokines IFN- $\gamma(\mathbf{a})$ and IL-2 (b), and the Th 2 cytokine IL-4 (c) was analyzed by ELISA. Means and SE were calculated from 5 mice/group. ${ }^{*} \mathrm{p}<0.01$ vs. unstressed WT control, ${ }^{* *} \mathrm{p}<0.01$ vs. stressed WT mice. numbers, we first examined the expression of $\beta$-arrestin 2 with or without physical restraint by real-time quantitative RT-PCR (fig. 1a) and Western blot analysis (fig. 1b). The expression of $\beta$-arrestin 2 in the spleen was significantly decreased following physical restraint (fig. la, b). We then determined the role of $\beta$-arrestin 2 in the physically stressed immune system. We used a knockout mouse line which lacks the $\beta$-arrestin $2[38,39]$ and is therefore a very powerful tool for investigating the role of $\beta$-arrestin 2 in the restraint stress-induced splenocyte reduction. We subjected $\beta$-arrestin 2 knockout mice and wild-type mice (controls) to 12-hour physical restraint daily for 2 days. Physical stress of wild-type mice induced a $35 \%$ reduction in splenocyte numbers compared to unstressed controls. Interestingly, the physical restraint of $\beta$-arrestin 2 knockout mice caused approximately a $65 \%$ splenocyte reduction compared to unstressed controls (fig. 1c). Collectively, our data suggest that $\beta$-arrestin 2 plays a pivotal role in the restraint stress-induced reduction in splenocyte numbers.

\section{Effect of $\beta$-Arrestin 2 on the Balance between $T$}

Helper 1 and 2 Cytokine Levels in Restraint Stress

$\beta$-Arrestin 2 is the predominant arrestin protein in $\mathrm{T}$ and $B$ lymphocytes $[26,35]$. Increasing evidence demonstrated that $\beta$-arrestin 2 mediates some important immune responses, such as the regulation of chemotactic responses and granule release due to its scaffold and adaptor functions $[19,35]$. Recently, we have reported that restraint stress caused dramatic decreases in $\mathrm{T}$ helpertype (Th) 1 cytokine IFN- $\gamma$ and IL-2 levels but an increase in the Th2 cytokine IL- 4 in wild-type mice $[8,14]$. Therefore, we next determined the effects of $\beta$-arrestin 2 on Th1 and Th 2 cytokine production following restraint stress. Two days after restraint stress of $\beta$-arrestin 2deficient mice and wild-type mice, culture supernatants from concanavalin A-stimulated splenocytes were analyzed for the levels of Th1 cytokines, IFN- $\gamma$ and IL-2, and the Th2 cytokine IL- 4 by ELISA. We found that splenocytes from stressed wild-type mice produced dramatically less IFN- $\gamma$ (fig. 2a) and IL-2 (fig. 2b) and significantly more IL-4 (fig. 2c) than splenocytes from unstressed wild-type mice. Although stress dramatically alters the production of Th1 and Th 2 cytokines in $\beta$-arrestin 2 knockout mice compared with unstressed $\beta$-arrestin 2 knockout mice, intriguingly, the stress dramatically enhances alterations in Th1 and Th2 cytokines in $\beta$-arrestin 2 knockout mice compared with the wild-type mice (fig. 2). Thus, the inhibition of Th1 cytokines and the induction of Th2 cytokines by stress are mediated through a $\beta$-arrestin 2-dependent mechanism.

\section{$\beta$-Arrestin 2 Deficiency in Mice Enhances the} Stress-Induced Suppression of the DTH Response

Chronic stress suppressed the DTH response $[4,32]$. DTH responses are antigen-specific T cell-mediated immune reactions $[4,33,34]$. Recent evidence supports that $\beta$-arrestin 2 is the predominant arrestin protein in Tlym- 


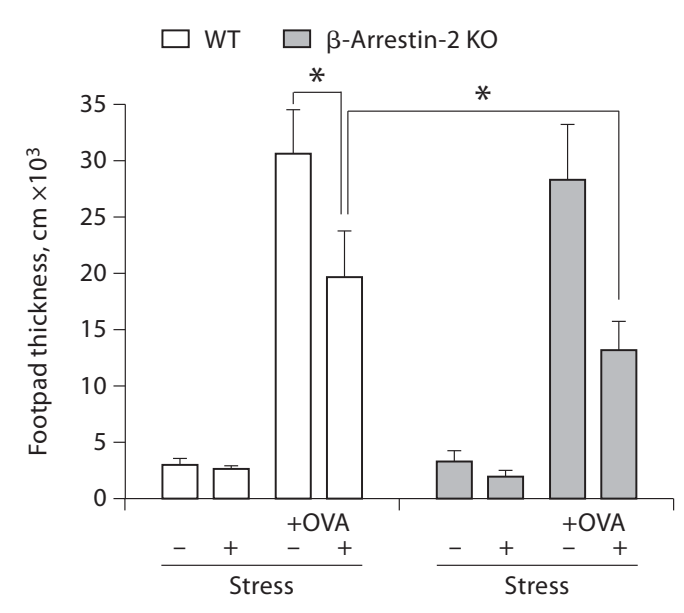

Fig. 3. Restraint stress-induced suppression of the DTH response was enhanced in $\beta$-arrestin 2-deficient mice. Wild-type (WT) and $\beta$-arrestin 2 -deficient mice $(\beta$-arrestin $2 \mathrm{KO})$ were immunized with OVA (injection of $100 \mu \mathrm{g}$ s.c.) in complete Freund's adjuvant on the 1st day of stress followed by a boost with OVA (injection of $20 \mu \mathrm{g}$ s.c.) in incomplete Freund's adjuvant on the 7 th day. Mice were subjected to a 12-hour physical restraint daily for 3 days. In all groups, DTH (hind footpad) was assessed on day 10 in a blind fashion using a caliper meter. ${ }^{*} \mathrm{p}<0.01$ vs. the indicated groups.

phocytes [19]. Therefore, we next investigated the effect $\beta$-arrestin 2 on the DTH response during physical stress in $\beta$-arrestin 2 knockout and wild-type mice. We observed that stressing mice for 2 days also suppressed the DTH response (data not shown). However, in mice, a 3 -day stress exposure induced more suppression of the DTH response compared with a 2-day stress exposure. Thus, we reported the data from mice stressed for 3 days. As shown in figure 3, restraint stress of immunized wildtype mice significantly decreased footpad thickness compared to that of immunized unstressed wild-type mice. Interestingly, restraint stress further decreased footpad thickness in $\beta$-arrestin 2 knockout mice compared with wild-type mice. These results suggest that $\beta$-arrestin 2 plays an important role in $\mathrm{T}$ cell-mediated immunity during stress.

Inhibition of PI3K in $\beta$-Arrestin 2-Deficient Mice

Exerts an Additive Effect on the Stress-Induced

Splenocyte Reduction

We have recently reported that PI3K signaling plays an important role in the stress-induced reduction in the number of splenocytes $[8,12]$. Recent studies have shown that $\beta$-arrestin 2 regulates the PI3K/Akt signaling pathway [29]. Thus, to determine the role of $\beta$-arrestin 2 in the PI3K-mediated reduction in the number of splenocytes induced by stress, we subjected $\beta$-arrestin 2 knockout mice and wild-type mice to stress. One hour before the initiation of each stress cycle, we administered the PI3K inhibitors LY294002 or wortmannin, which have been widely used to study the role of PI3K in the immune system both in vitro and in vivo $[8,10,32,40]$. As shown in figure 4a, inhibition of PI3K by LY294002 administration did not dramatically change the number of splenocytes in either wild-type or $\beta$-arrestin 2-deficient mice in the absence of physical stress. However, in the presence of physical stress, PI3K inhibition significantly decreased the number of splenocytes in both wild-type and $\beta$-arrestin 2-deficient mice compared with their stressed control mice (without LY294002 administration). LY294002 administration exerted an additive effect on stress-induced splenocyte reduction in both wild-type mice and $\beta$-arrestin 2-deficient mice. Interestingly, in the presence of stress, LY294002 administration in $\beta$-arrestin 2 -deficient mice resulted in a greater splenocyte reduction than either LY294002 administration in wild-type mice or in $\beta$-arrestin 2-deficient mice without LY294002 administration (fig. 4a). Similar results were observed for the other PI3K inhibitor wortmannin (fig. 4b). Collectively, these data suggest that it is possible that $\beta$-arrestin 2 plays a role in PI3K-mediated splenocyte reduction induced by stress.

\section{Discussion}

Physical and psychological stress can change the immune system in both humans and animals $[1,6]$. Stress is a known risk factor for human diseases, such as autoimmune and infectious diseases [4, 5, 41]. Stress-induced T-cell dysfunction has been observed in persons under various stressors $[42,43]$. Numerous experimental systems have been utilized to investigate how stress alters immune functions. However, little progress has been made in understanding physical and psychological stressinduced immune suppression. Recent evidence suggests that $\beta$-arrestin 2 plays an important role in regulating immune responses $[19,21]$. However, the effects of $\beta$-arrestin 2 on stress-induced immune responses are unknown. We speculated that high levels of $\beta$-arrestin 2 may be responsible for the splenocyte reduction induced by restraint stress. In this study, we demonstrated that 


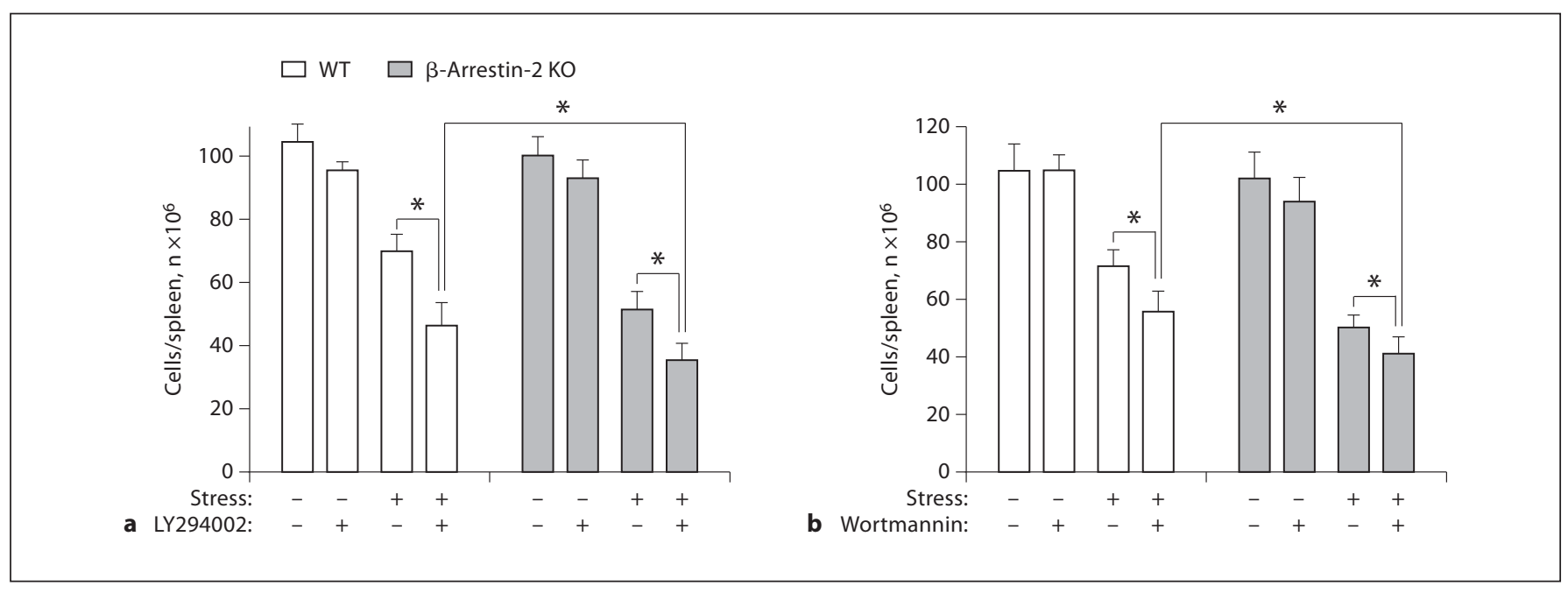

Fig. 4. PI3K inhibition increases lymphocyte reduction in wildtype (WT) and $\beta$-arrestin 2 -deficient ( $\beta$-arrestin $2 \mathrm{KO}$ ) mice following stress. We subjected $\beta$-arrestin 2 -deficient and WT mice aged $6-8$ weeks to $12 \mathrm{~h}$ of physical stress daily. LY294002 (1 mg/ $25 \mathrm{~g}$ body weight; a) or wortmannin $(25 \mu \mathrm{g} / 25 \mathrm{~g}$ body weight; b) was administered intraperitoneally $1 \mathrm{~h}$ before the initiation of the stress cycle. Two days after stress, total splenocytes were counted. Means and SE were calculated from 6 mice/group. ${ }^{*} \mathrm{p}<0.01$ vs. the indicated groups. lack of $\beta$-arrestin 2 in mice increases the sensitivity to stress-induced splenocyte reduction (fig. 1b). Our previous studies have shown that restraint stress of mice induces a reduction in splenocyte numbers through a cellapoptotic mechanism [10]. We followed our stress mouse model as described in our previous studies [10]. The reduction in splenocytes induced by stress could be mediated by two possible mechanisms: cell death or emigration. In our published work [10], we determined cell death in histological sections of the spleen using a TUNEL technique. We found that in the spleen of stressed mice a significant number of cells was undergoing apoptosis, whereas only a few apoptotic cells were detected in the spleen of control mice. Thus, a physical restraint-induced reduction in splenocyte numbers is likely due to the induction of apoptosis rather than the mobilization of splenocytes. Therefore, we did not further determine the role of emigration in the same restraint stress mouse model in our current study. The role of $\beta$-arrestin 2 in stress-induced apoptosis will be investigated in future studies.

We have recently reported that chronic stress induces an imbalance in the Th1 and Th2 responses [14]. In the present study, we extended these observations to demonstrate that dysfunction of $\beta$-arrestin 2 ( $\beta$-arrestin 2 knockout) had a stronger inhibitory effect on Th1 cytokine levels than in wild-type mice. Of great significance, dysfunction of $\beta$-arrestin 2 increases stress-induced sup- pression of the DTH response. Thus, these data suggest that restraint stress may initiate an immunosuppressive process in animals resulting in the modulation of a $\beta$ arrestin 2-mediated signaling pathway. A limitation of the study is the use of $\beta$-arrestin 2-deficient mice. $\beta$-Arrestin 2 transgenic mice (overexpression of $\beta$-arrestin 2 ) will be used in future studies.

Growing evidence reveals that $\beta$-arrestin 2 induces activation of PI3K/Akt [20, 21]. Anti-apoptotic proteins inhibit apoptosis via activating specific signaling pathway(s), such as the PI3K-mediated pathway. It has been established that inhibition of PI3K-mediated signaling sensitizes cells to apoptotic stimuli [44]. We and others have shown that LY294002, a PI3K inhibitor, caused inhibition of cell proliferation and induction of cell apoptosis, and that inhibition of PI3K-mediated signaling dramatically enhanced the sensitivity of cell apoptosis [12, $32,44]$. Our previous studies have demonstrated that inhibition of PI3K by administration of LY294002 or wortmannin before restraint of mice caused a greater reduction in splenocyte numbers $[8,12]$. We speculated that $\beta$-arrestin 2 plays a role in PI3K-mediated splenocyte reduction induced by stress. To test this hypothesis, we administered the PI3K inhibitor LY294002 or wortmannin prior to restraint stress in $\beta$-arrestin 2 knockout and wild-type mice. We observed that pharmacological inhibition of PI3K activity by LY294002 or wortmannin be- 
fore physical restraint caused a greater reduction in the number of splenocytes than stress did alone. Interestingly, we found that in the presence of stress, inhibition of $\mathrm{PI} 3 \mathrm{~K}$ in $\beta$-arrestin 2-deficient mice resulted in a greater splenocyte reduction than either inhibition of PI3K in wild-type mice or in $\beta$-arrestin 2-deficient mice without inhibition of PI3K (fig. 4). Therefore, these data suggest that it is possible that $\beta$-arrestin 2 plays a role in PI3Kmediated splenocyte reduction induced by stress. However, future studies are required to elucidate the precise role of $\beta$-arrestin 2-mediated PI3K.

In summary, to the best of our knowledge, this study is the first report to demonstrate that a deficiency in $\beta$ - arrestin 2 augments stress-induced immune suppression. Our data suggest that $\beta$-arrestin 2 may serve as a potential therapeutic target to promote the activation of protective signaling, such as PI3K/Akt signaling.

\section{Acknowledgments}

This work was supported by the National Institutes of Health (grant DA020120-03A1) and the ETSU Research Development Committee (D. Yin and G. Hanley - grant 07-026M). The authors wish to express their appreciation to Dr. Robert Lefkowitz, Duke University Medical School, for providing $\beta$-arrestin knockout mice.

\section{References}

1 Frieri M: Neuroimmunology and inflammation: implications for therapy of allergic and autoimmune diseases. Ann Allergy Asthma Immunol 2003;90:34-40.

-2 Yang EV, Glaser R: Stress-associated immunomodulation and its implications for responses to vaccination. Expert Rev Vaccines 2002;1:453-459.

-3 Sonnenfeld G: Immune responses in space flight. Int J Sports Med 1998;19(suppl 3):S195-S202.

4 Dhabhar FS, McEwen BS: Acute stress enhances while chronic stress suppresses cellmediated immunity in vivo: a potential role for leukocyte trafficking. Brain Behav Immun 1997;11:286-306.

-5 Shi Y, Devadas S, Greeneltch KM, Yin D, Allan MR, Zhou JN: Stressed to death: implication of lymphocyte apoptosis for psychoneuroimmunology. Brain Behav Immun 2003; 17(suppl 1):S18-S26.

6 Reiche EM, Nunes SO, Morimoto HK: Stress, depression, the immune system, and cancer. Lancet Oncol 2004;5:617-625.

-7 Quan N, Avitsur R, Stark JL, He L, Shah M, Caligiuri M, Padgett DA, Marucha PT, Sheridan JF: Social stress increases the susceptibility to endotoxic shock. J Neuroimmunol 2001;115:36-45.

8 Zhang Y, Zhang Y, Miao J, Hanley G, Stuart C, Sun X, Chen T, Yin D: Chronic restraint stress promotes immune suppression through Toll-like receptor 4-mediated phosphoinositide 3-kinase signaling. J Neuroimmunol 2008;204:13-19.

-9 Zorrilla EP, Luborsky L, McKay JR, Rosenthal R, Houldin A, Tax A, McCorkle R, Seligman DA, Schmidt K: The relationship of depression and stressors to immunological assays: a meta-analytic review. Brain Behav Immun 2001;15:199-226.
10 Yin D, Tuthill D, Mufson RA, Shi Y: Chronic restraint stress promotes lymphocyte apoptosis by modulating CD95 expression. J Exp Med 2000;191:1423-1428.

- 11 Yin D, Zhang Y, Stuart C, Miao J, Zhang Y, Li C, Zeng X, Hanley G, Moorman J, Yao Z, Woodruff M: Chronic restraint stress modulates expression of genes in murine spleen. J Neuroimmunol 2006;177:11-17.

12 Zhang Y, Foster R, Sun X, Yin Q, Li Y, Hanley G, Stuart C, Gan Y, Li C, Zhang Z, Yin D: Restraint stress induces lymphocyte reduction through p53 and PI3K/NF- $\mathrm{KB}$ pathways. J Neuroimmunol 2008;200:71-76.

13 Cao L, Hudson CA, Moynihan JA: Chronic foot shock induces hyperactive behaviors and accompanying pro- and anti-inflammatory responses in mice. J Neuroimmunol 2007; 186:63-74.

14 Zhang Y, Woodruff M, Zhang Y, Miao J, Hanley G, Stuart C, Zeng X, Prabhakar S, Moorman J, Zhao B, Yin D: Toll-like receptor 4 mediates chronic restraint stress-induced immune suppression. J Neuroimmunol 2008;194:115-122.

15 Lefkowitz RJ, Shenoy SK: Transduction of receptor signals by beta-arrestins. Science 2005;308:512-517.

16 Moore CA, Milano SK, Benovic JL: Regulation of receptor trafficking by GRKs and arrestins. Annu Rev Physiol 2007;69:451-482.

17 Buchanan FG, DuBois RN: Emerging roles of beta-arrestins. Cell Cycle 2006;5:20602063.

-18 Nelson CD, Perry SJ, Regier DS, Prescott SM, Topham MK, Lefkowitz RJ: Targeting of diacylglycerol degradation to M1 muscarinic receptors by beta-arrestins. Science 2007; 315:663-666.

19 Fong AM, Premont RT, Richardson RM, Yu YR, Lefkowitz RJ, Patel DD: Defective lymphocyte chemotaxis in beta-arrestin2- and GRK6-deficient mice. Proc Natl Acad Sci USA 2002;99:7478-7483.
20 Revankar CM, Vines CM, Cimino DF, Prossnitz ER: Arrestins block G proteincoupled receptor-mediated apoptosis. J Biol Chem 2004;279:24578-24584

21 Wang Y, Tang Y, Teng L, Wu Y, Zhao X, Pei G: Association of beta-arrestin and TRAF6 negatively regulates Toll-like receptor-interleukin 1 receptor signaling. Nat Immunol 2006;7:139-147.

22 Franke TF, Kaplan DR, Cantley LC: PI3K: downstream AKTion blocks apoptosis. Cell 1997;88:435-437.

23 Cantley LC: The phosphoinositide 3-kinase pathway. Science 2002;296:1655-1657.

24 Okkenhaug K, Vanhaesebroeck B: PI3K in lymphocyte development, differentiation and activation. Nat Rev Immunol 2003;3: 317-330.

25 Williams DL, Li C, Ha T, Ozment-Skelton T, Kalbfleisch JH, Preiszner J, Brooks L, Breuel $\mathrm{K}$, Schweitzer JB: Modulation of the phosphoinositide 3-kinase pathway alters innate resistance to polymicrobial sepsis. J Immunol 2004; 172:449-456.

26 Arruda MA, Rossi AG, de Freitas MS, BarjaFidalgo C, Graca-Souza AV: Heme inhibits human neutrophil apoptosis: involvement of phosphoinositide 3-kinase, MAPK, and NFкВ. J Immunol 2004;173:2023-2030.

27 Povsic TJ, Kohout TA, Lefkowitz RJ: Betaarrestin1 mediates insulin-like growth factor 1 (IGF-1) activation of phosphatidylinositol 3-kinase (PI3K) and anti-apoptosis. J Biol Chem 2003;278:51334-51339.

28 Beaulieu JM, Sotnikova TD, Marion S, Lefkowitz RJ, Gainetdinov RR, Caron MG: An Akt/beta-arrestin 2/PP2A signaling complex mediates dopaminergic neurotransmission and behavior. Cell 2005;122: 261-273. 
-29 Kovacs JJ, Hara MR, Davenport CL, Kim J, Lefkowitz RJ: Arrestin development: emerging roles for beta-arrestins in developmental signaling pathways. Dev Cell 2009;17:443458.

-30 Sheridan JF, Dobbs C, Jung J, Chu X, Konstantinos A, Padgett D, Glaser R: Stress-induced neuroendocrine modulation of viral pathogenesis and immunity. Ann NY Acad Sci 1998;840:803-808.

-31 Yin D, Zhang L, Wang R, Radvanyi L, Haudenschild C, Fang Q, Kehry MR, Shi Y: Ligation of CD28 in vivo induces CD40 ligand expression and promotes B cell survival. J Immunol 1999;163:4328-4334.

-32 Yin D, Woodruff M, Zhang Y, Whaley S, Miao J, Ferslew K, Zhao J, Stuart C: Morphine promotes Jurkat cell apoptosis through pro-apoptotic FADD/P53 and anti-apoptotic PI3K/Akt/NF- $\kappa$ B pathways. J Neuroimmunol 2006;174:101-107.

-33 Dhabhar FS, McEwen BS: Enhancing versus suppressive effects of stress hormones on skin immune function. Proc Natl Acad Sci USA 1999;96:1059-1064.
\$34 Kim SH, Bianco NR, Shufesky WJ, Morelli AE, Robbins PD: MHC class II+ exosomes in plasma suppress inflammation in an antigen-specific and Fas ligand/Fas-dependent manner. J Immunol 2007;179:2235-2241.

35 Moorman J, Zhang Y, Liu B, LeSage G, Chen Y, Stuart C, Prayther D, Yin D: HIV-1 gp120 primes lymphocytes for opioid-induced, beta-arrestin 2-dependent apoptosis. Biochim Biophys Acta 2009;1793:1366-1371.

36 Zhao M, Zhou G, Zhang Y, Chen T, Sun X, Stuart C, Hanley G, Li J, Zhang J, Yin D: Beta-arrestin2 inhibits opioid-induced breast cancer cell death through Akt and caspase-8 pathways. Neoplasma 2009;56:108-113.

-37 Li Y, Sun X, Zhang Y, Huang J, Hanley G, Ferslew KE, Peng Y, Yin D: Morphine promotes apoptosis via TLR2, and this is negatively regulated by beta-arrestin 2 . Biochem Biophys Res Commun 2009;378:857-861.

>38 Bohn LM, Gainetdinov RR, Lin FT, Lefkowitz RJ, Caron MG: Mu-opioid receptor desensitization by beta-arrestin- 2 determines morphine tolerance but not dependence. Nature 2000;408:720-723.

-39 Bohn LM, Lefkowitz RJ, Gainetdinov RR, Peppel K, Caron MG, Lin FT: Enhanced morphine analgesia in mice lacking beta-arrestin 2 . Science 1999;286:2495-2498.
40 Adi S, Wu NY, Rosenthal SM: Growth factor-stimulated phosphorylation of Akt and p70(S6K) is differentially inhibited by LY294002 and wortmannin. Endocrinology 2001;142:498-501.

41 Hawkley LC, Cacioppo JT: Stress and the aging immune system. Brain Behav Immun 2004;18:114-119.

42 Makarenkova VP, Bansal V, Matta BM, Perez LA, Ochoa JB: CD11b+/Gr-1+ myeloid suppressor cells cause $\mathrm{T}$ cell dysfunction after traumatic stress. J Immunol 2006;176:20852094.

43 Kono K, Takahashi A, Iizuka H, Fujii H, Sekikawa T, Matsumoto Y: Effect of oesophagectomy on monocyte-induced apoptosis of peripheral blood T lymphocytes. Br J Surg 2001;88:1110-1116.

44 Osaki M, Kase S, Adachi K, Takeda A, Hashimoto $\mathrm{K}$, Ito $\mathrm{H}$ : Inhibition of the PI3K-Akt signaling pathway enhances the sensitivity of Fas-mediated apoptosis in human gastric carcinoma cell line, MKN-45. J Cancer Res Clin Oncol 2004;130:8-14 